\title{
Correction to: Chemotherapy and Standard Treatment Options
}

Mary Hesdorffer and Gleneara E. Bates-Pappas

\section{Correction to:}

Chapter 5 in: M. Hesdorffer, G. E. Bates-Pappas (eds.),

Caring for Patients with Mesothelioma: Principles and Guidelines, https://doi.org/10.1007/978-3-319-96244-3_5

The original version of the book was published in May 2019 without a key information about FDA approval for mesothelioma. The same has been included in this updated version. 